\title{
The dynamics of selected local inflammatory markers to talc in the treatment of malignant pleural effusions
}

\author{
Petr Habala , Karolina Jankovicova ${ }^{b}$, Nedal Omran ${ }^{a}$, Katerina Kondelkova ${ }^{b}, J a n$ Krejsek ${ }^{b}$, Jiri Mandak ${ }^{a}$
}

\begin{abstract}
Background. Malignant pleural effusions accumulate in the space between the visceral (inner) layer covering the lungs and the parietal (outer) layer covering the chest wall. Larger effusions compress the pulmonary parenchyma resulting in increasing dyspnoea. Treatment is always local and palliative. Among others, chemical pleurodesis using talc can be performed in selected patients. Talc is hydrated magnesium silicate (chemically $\mathrm{H}_{2} \mathrm{Mg}_{3}\left(\mathrm{SiO}_{3}\right)_{4}$ ) and has been used for pleurodesis since 1935. Videothoracoscopic talc powder insufflation (talc poudrage) is the most effective. However, markers of inflammatory reactions to extraneous substances like talc are not fully understood. The aim of this study was to assess the course of local inflammatory changes in the pleural cavity after talc insufflation.

Methods. The Department of Cardiac Surgery of the Faculty of Medicine and University Hospital in Hradec Kralove, treated 47 patients aged 65 on average; 29 males and 18 females with proven recurrent malignant pleural effusion of various aetiologies from January 2009 to December 2010. They were retrospectively divided into group A (40 patients) without recurring effusion, and group B (7 patients) with recurring effusion and the need for thoracentesis or chest drainage during the 9-month monitoring.

Results. Major findings were made in soluble forms of cell receptors. Group B showed statistically higher levels of the anti-inflammatory form of SCD-163 receptor in pleural fluid before the talc poudrage. This showed limited ability to create an adequate inflammatory response to external stimuli. This group also showed lower levels of the inflammatory form of sTLR-2 receptor immediately after the talc insufflation. This revealed low local reactivity to external stimuli. The effect of the treatment was not influenced by morphologic tumour type. No statistically significant differences in postoperative complications were found. This confirmed the safety of both videothoracoscopy and treatment.

Conclusions. There was no correlation between the type of malignant affection and the outcome of the chemical pleurodesis. Patients with relapsing effusion have higher values of concentration of anti-inflammatory sCD-163 in pleural fluid even before the application of talc, and lower levels of concentration of inflammatory sTLR-2 immediately after application of talc.
\end{abstract}

Key words: malignant pleural effusion,thoracoscopy, talc, sCD-163, sTLR-2

Received: May 9, 2012; Accepted with revision: October 8, 2012; Available online: December 7, 2012 http://dx.doi.org/10.5507/bp.2012.095

${ }^{a}$ Department of Cardiac Surgery, Faculty of Medicine in Hradec Kralove, Charles University in Prague and University Hospital in Hradec Kralove, Czech Republic

${ }^{b}$ Department of Clinical Immunology and Allergy, Faculty of Medicine in Hradec Kralove, Charles University in Prague and University Hospital in Hradec Kralove

Corresponding author: Jiri Mandak, e-mail:jiri.mandak@centrum.cz

\section{INTRODUCTION}

Malignant effusion takes place in the pathologically changed space between the parietal and visceral pleura most often in patients with cancer. Under physiological condition, the pleural cavity is the space between parietal and visceral pleura (10-20 $\mu \mathrm{m}$ width), which is filled with serous fluid- $0.1-0.2 \mathrm{~mL} / \mathrm{kg}$ total body weight. The pleural surface is enlarged by the microvillus system. In the adult, the surface of the pleural membranes covers about 4 square meters ${ }^{1}$.

Pleural effusion is caused by either exceeding the resorptive capacity of the pleura, which is about $700 \mathrm{~mL} /$ day (e.g. in the case of increased hydrostatic pressure, decreased oncotic pressure, decreased intrapleural pressure, increased capillary permeability or fluid movement from the peritoneal cavity etc.) or decrease in the absorption capacity of the pleural lymphatic drainage system (in case of malignant involvement of the lymphatic vessels), or a combination of both causes ${ }^{2,3}$.

Malignant effusions account for about $15-30 \%$ of all pleural effusions, most often in cases of breast and lung carcinoma ${ }^{4,5}$. In palliative oncological treatment (POT), relieving thoracentesis and chest drainage are performed ${ }^{6}$.

Repeating these can cause pneumothorax or haemothorax and damage to pulmonary tissue or intercostal vessels. Empyema of the thorax is very serious.

Talc insufflation thoracoscopically can be done in selected groups of patients with malignant pleural effusion and preserved lung expandibility ${ }^{7}$, Effective contact of parietal and visceral pleura due to the talc then ensures no fluid return ${ }^{8}$. In case of sustained collapse of the pulmonary parenchyma after thoracentesis (trapped lung syndrome) pleurodesis is contraindicated and other methods of treatment should be considered ${ }^{9}$. The principle of pleurodesis is elimination of the space between 
the visceral and parietal pleura by inducing aseptic pleuritis ${ }^{10,11}$. This procedure is called chemical pleurodesis. Many substances have been tested to achieve this aim e.g. silver nitrate, iodopovidone, doxycycline, bleomycine and Corynebacterium parvum vaccine with different outcomes $^{12}$. The use of Corynebacterium parvum for pleurodesis is not recommended due to the increasing number of anaphylactic reactions ${ }^{13,14}$.

The most effective is application of talc in powder ${ }^{15}$. This is effective in up to $90 \%$ of cases $^{16}$. The use of talc is based on experience, with a dose up to $5 \mathrm{~g}$ (ref. ${ }^{10,17}$ ).

To date, there has only been sporadic evaluation of the general inflammatory reactions of the organism to extraneous substances while evaluation of local inflammatory markers for use in clinical medicine is the subject of ongoing clinical studies ${ }^{18,19}$. In the past, some biochemical markers of effusion in relation to survival prognosis were examined. For example, if the concentration of glucoses is $<600 \mathrm{mg} / \mathrm{L}$, the prognosis is adverse ${ }^{20}$.

More recent studies have evaluated the relation of survival time and pleurodesis success rate to $\mathrm{pH}$ of pleural fluid ${ }^{21}$. Treatment success can be evaluated by a large number of markers such as adenosindeaminase ${ }^{22}$.

\section{MATERIAL AND METHOD}

From January 2009 to December 2010, at the Department of Cardiac Surgery of Medicine Faculty of Charles University and University Hospital in Hradec Kralove, 47 patients with cytologically proven recurring malignant pleural effusion were recommended for thoracoscopic talc poudrage.

The functional status of the patient was assessed using the Karnofsky Performance Status (KPS) index > 75\%, and a realistic prognosis of survival time (LE) $>3$ months in relation to basic diagnosis. The patients consisted of those with proven re-expansion of pulmonary tissue by fluoroscopy after removal of the effusion by previous thoracentesis.

The removal of the effusion was performed by videothoracoscopy, gradually in portions of $500 \mathrm{~mL}$ to prevent complications - re-expansion pulmonary oedema (RPE). After removing the fluid, a biopsy of parietal pleura was performed and $5 \mathrm{~g}$ of talc in powder form was applied. After talc poudrage a visual check for bleeding and reexpansion of the lung was performed. A chest tube was inserted using a video camera port.

Pleural fluid examination was done at three intervals during pleurodesis: $1^{\text {st }}$ - before the thoracoscopic procedure, $2^{\text {nd }}-2 \mathrm{~h}$ after the terminating thoracoscopic procedure with talc insufflation $3^{\text {rd }}-24 \mathrm{~h}$ after the thoracoscopic procedure. The samples were examined for selected indicators of inflammation. The waste via chest drain over $24 \mathrm{~h}$ was $<150 \mathrm{~mL}$. The effect of pleurodesis was evaluated by ultrasound at 1, 3, 6, 9 months.

\section{Statistical analysis}

Flow cytometry data were analysed by FlowJo software (Tree Star, USA). Clinical data, flow cytometry results and ELISA results were statistically analysed by MedCalc statistical software. Comparison between pleural effusion collection in the three intervals was assessed by paired t-tests or by Wilcoxon test according to the normality of the data. Differences between groups were tested by t-tests or Mann-Whitney test according to the normality of the data. Categorical data were tested by the Fisher exact test. Statistical significance was set at $P=0.05$.

The study protocol was approved by the Ethics Committee of the University Hospital in Hradec Kralove and informed consent was obtained from all participants.

\section{RESULTS}

Patients with pleural carcinomatos is of various aetiologies consisted of $29(61.7 \%)$ men and $18(38.3 \%)$ women (Table 1), aged from 42 to 80 years old, average 65 years old. The average time of operation was $44 \pm$ $12 \mathrm{~min}$. The average time of thoracoscopic drainage was $5 \pm 2$ days. The average time of hospitalization was $7 \pm$ 2 days. The cause of one death $28 \mathrm{~h}$ after the operation was hypercapnic respiratory insufficiency.

Retrospectively, the patients were divided into Group A (40 patients) treated successfully without recurring effusion, and Group B (7 patients), where during the $9^{\text {th }}$ - month of monitoring, it was necessary to perform repeated thoracenthesis or chest drainage due to recurring effusion (Table 2).

Table 1. Basic diagnoses depending on the sex of patients.

\begin{tabular}{lcc}
\hline Diagnosis & Male (\%) & Female (\%) \\
\hline Carcinoma of lungs & & \\
Metastases & $15(51.7)$ & $2(11.1)$ \\
$\quad$ - breast & 0 & $6(33.3)$ \\
- ovary & 0 & $2(11.1)$ \\
- GIT & $8(27.5)$ & $2(11.1)$ \\
- lymphoma & $1(3.4)$ & 0 \\
- Grawitz & 0 & $1(5.5)$ \\
Malignant mesothelioma & $3(10.3)$ & $2(11.1)$ \\
Malignant thymoma & $2(6.8)$ & 0 \\
Neurofibrosarcoma & 0 & $1(5.5)$ \\
Malignant struma & 0 & $1(5.5)$ \\
Chondrosarcoma & 0 & $1(5.5)$ \\
\hline$\sum$ & 29 & 18 \\
\hline
\end{tabular}

The groups differed in volume of effusion in the time of admission to the operation. At the time of discharge, there were no statistically significant differences in effusion volume. During the first check up after 1 month, Group B showed a significant rise in effusion volume and the trend to statistical difference lasted for the whole monitored period.

The dynamics of local inflammatory manifestations were monitored by changes in pleural values of antiinflammatory soluble sCD-163 receptor. The concen- 
Table 2. Development of pleural effusion quantity between Groups A and B in mL.

\begin{tabular}{lcrc}
\hline Time (month) & A & B & $P$-value \\
\hline Ad & $1000(500-2000)$ & $1500(1000-2500)$ & 0.0014 \\
$\mathrm{D}$ & $200(100-500)$ & $400(300-600)$ & 0.121 \\
1 & $200(100-500)$ & $800(300-1000)$ & $<0.001$ \\
3 & $250(150-500)$ & $700(300-1000)$ & $<0.001$ \\
6 & $250(150-400)$ & $950(800-1250)$ & $<0.001$ \\
9 & $250(200-400)$ & $1150(850-1200)$ & $<0.001$ \\
\hline
\end{tabular}

* - median (minimum - maximum), Ad - admission, D - discharge

A - group without exudate relapsing, B - group with exudate relapsing

Table 3. Development of local inflammatory reaction in Groups A and B - sCD-163 (ng/mL) in pleural fluid.

\begin{tabular}{cccc}
\hline Time $(\mathrm{h})$ & A & B & $P$-value \\
\hline 0 & $1128(425-5541)$ & $4275(2353-4525)$ & 0.001 \\
2 & $936(45-2231)$ & $2346(1118-5524)$ & 0.028 \\
24 & $695(314-1645)$ & $1030(658-1479)$ & 0.10 \\
\hline
\end{tabular}

* - median (minimum - maximum),A - group without exudate relapsing, B - group with exudate relapsing

Table 4. Development of local inflammatory reaction in Groups A and B - sTLR-2 $(\mathrm{ng} / \mathrm{mL})$ in pleural fluid.

\begin{tabular}{cccc}
\hline Time $(\mathrm{h})$ & A & B & $P$ - value \\
\hline 0 & $33.5(0-718)$ & $33(12-236)$ & 0.638 \\
2 & $180(27-656)$ & $50(0-204)$ & 0.002 \\
24 & $415.5(17-987)$ & $224(116-431)$ & 0.016 \\
\hline
\end{tabular}

* - median (minimum - maximum), A - group without exudate relapsing, B - group with exudate relapsing

trations of this receptor showed statistically significant differences between Groups even before the talc insufflation $(\mathrm{P}<0.001)$. A statistically significant difference between Groups A and B was still noticeable $2 \mathrm{~h}$ after the talc instillation into pleural cavity $(\mathrm{P}=0.028)$ (Table 3$)$.

The dynamics of changes in concentrations of inflammatory soluble sTLR-2 receptor values in pleural effusion showed a significant rise in patients with successful treatment effects (A) as early as $2 \mathrm{~h}$ after the talc poudrage $(P=0.002)$ and this rise was recorded during the whole monitored period. Input values in both groups were identical (Table 4).

\section{DISCUSSION}

There was no difference between the groups in basic demographics. There was no correlation between type of malignancy and treatment outcome. This has two aspects. First, it is a correct indication for surgical interventions in the remission of the basic disease. Second, any pleural tumorous disease due to effusion is similar. In malignancies, the mechanism of effusion development is not only due to blockage of lymphatic capillaries but also increase in capillary permeability and imbalance of the Starling equation which regulates reabsorption of pleural fluid.
A negative outcome of pleurodesis can be determined by the size of the tumour mass in the pleural cavity. Another factor is atelectatic involvement of the lung parenchyma caused by endobronchial tumour obstruction, which can cause trapped lung syndrome. This can explain the low success rate of the pleurodesis in cases of mesothelioma and lung cancer ${ }^{23,24}$.

Talc has a direct effect on tumour mass in the pleural cavity. It may suppress angiogenesis via endostatin and affect the apoptosis of tumour cells. In experiments, cultured rabbit pleural mesothelial cells (PMC) were exposed to talc for 6,24 , or $48 \mathrm{~h}$ and assessed for viability, necrosis, and apoptosis by flow cytometry ${ }^{25}$.

Pleurodesis by talc is the optimal treatment for malignant pleural effusion. Talc particles directly induce mesothelial cells to produce inflammatory cytokines, mainly IL-8, VEGF (vascular endothelial growth factor), and MCP-1 (monocyte chemotactic protein-1) (ref. ${ }^{26}$ ). These pro-inflammatory changes are followed by rapid polymorphonuclear neutrophil influx into the pleural space ${ }^{27}$. We observed this trend in our study as relative number of polymorphonuclear neutrophils increased from 33.07\% preoperatively to $90.21 \%$ after talkage. There is also evidence that talc enhances intercellular adhesion molecule-1 (ICAM-1) expression in pleural mesothelial cells ${ }^{28}$. Pleural mesothelial cells treated by talc secrete bFGF 
(basic fibroblast growth factor) and TGF $\beta$ (transforming growth factor $\beta$ ) responsible for fibroblast activation, and enhanced fibrogenesis including collagen production resulting in effective pleural fibrosis ${ }^{29}$. Surgical intervention involves severe operational trauma. Anaesthesia and surgery result in changes in the dynamics of inflammatory indicators ${ }^{30}$. This results in activating the coagulation and fibrinolytic blood system, and triggering the cascade of the inflammatory response ${ }^{31,32}$. The beneficial effect of the inflammatory reaction is in its participation in the defence against infective agents. The result of a successful reaction is the healing of damaged tissue ${ }^{33}$.

The intensity of the inflammatory reaction depends among others on extraneous material. For this reason, the reaction in cardio surgical operations using extracorporeal circulation is stronger than that in operations that do not use $\mathrm{it}^{34-36}$

In the small number of operations of this study, we aimed to trigger an inflammatory reaction and increase its effect using an extraneous substance. We can measure a number of changes in the general reaction of the organism. General inflammatory changes are highly unspecified manifestations.

External stimuli induce danger signals in the body and identification of these is mediated by Toll-like receptors (TLR) (ref. $\left.{ }^{37}\right)$. The dynamics of general changes of the receptor response to inflammatory stimuli is known mostly from experiments ${ }^{37,38}$.

The expression of TLR-2 molecule on polymorphonuclear granulocytes has been studied with respect to infection, sepsis, surgical stress and other medical interventions. This early TLR-2 down-regulation may be the result of externalizing entire molecules rather than transcriptional regulation of TLR-2 biosynthesis ${ }^{39,40}$. The intensity of TLR-2 expression on granulocytes is also significantly reduced during cardiopulmonary bypass surgery ${ }^{41}$. Our study showed down-regulation of TLR2 expression on granulocytes during talc pleurodesis. However, we can only speculate about the direct effect of talc particles on granulocytes, cytokine influence or a combination of both.

CD-163 is a member of the scavenger receptor super family class B of the first subgroup. It is mapped to the region $\mathrm{p} 13$ on chromosome 12 . This scavenger receptor is selectively expressed in cells of monocyte and macrophage lineage exclusively. It also has other functions. It participates in adhesion to endothelial cells, in tolerance induction and tissue regeneration. Other very important functions of CD-163 are the clearance of hemoglobin in its cell-free form and participation in anti-inflammation in its soluble form, exhibiting cytokine-like functions ${ }^{42}$.

Our patients showed high levels of anti-inflammatory receptor $\mathrm{sCD}-163$ even before the application of talc in Group B in which the treatment was not successful. We can assume that these patients were exposed to other external factors causing inflammatory reactions. However, there were no statistically significant differences between the groups in general inflammatory indicators before the operation. There was no significant difference between the groups between the operation and the last thoracentesis, which could have influenced local changes in inflammatory indicators. where we can judge that a different reactivity of monitored indicators was influenced by different state of "readiness" or "exhaustion" of the organism.

When talc is insufflated in the pleural cavity, the inflammatory reaction, which causes chemical pleurodesis, can also produce adverse reactions. The failure of internal regulative mechanisms can cause serious organic damage with fatal results. It is not yet possible to predict the intensity of inflammatory reaction to external stimuli in order to prevent these complications.

The first efforts to influence the inflammatory process were experimental. Results, extrapolated from experiments, often fail in clinical practice. The examination of local parameters of inflammatory reactions, which would enable us to make clinical decisions, is still in the experimental stage ${ }^{43}$.

In clinical practice we work with a highly genetically heterogeneous spectrum of patients. For this reason, we can expect various inflammatory reactions.

\section{CONCLUSIONS}

In contrast to other studies, we found no correlation between the type of malignancy and the outcome of chemical pleurodesis.

No significant postoperative complications were recorded. This supports the safety of the videothoracoscopic method and chosen procedures.

In the current treatment procedures, inflammatory reaction on both parietal and visceral pleura only partially influences the resulting treating effect. The success of the reaction is influenced by biological status and metabolic activity. Effective, durable of both pleural membranes is essential.

For clinical practice, examination of sCD-163 in routine analysis using the ELISA method on samples of pleural fluid could be done. The fee for this examination is around 25 Euros.

To date, it has not been possible to influence systematically the pathological parameters corresponding to the sampled local inflammatory markers. The differences in results can be used to diagnose within hours after the operation, in some cases before hand and in selected patients it is hence possible to apply talc via the per-operatively placed chest drain.

From analysis of the dynamics of local immunological indicators we have gained some original knowledge. Patients with relapsing effusion have higher values of concentration of the anti-inflammatory sCD-163 in the pleural fluid even before the application of talc, and lower levels of concentration of inflammatory sTLR-2 immediately after application of talc. 


\section{ACKNOWLEDGEMENT}

Supported by the project Ministry of Health, Czech Republic for conceptual development of research organization 00179906.

\section{CONFLICT OF INTEREST STATEMENT}

Author's conflict of interest disclosure: The authors stated that there are no conflicts of interest regarding the publication of this article.

\section{REFERENCES}

1. Miserocchi G. Physiology of pleural fluid turnover. Eur Respir J 1997;10:219-25.

2. Lombardi G, Zustovich F, Nicoletto MO, Donach M, Artioli G, Pastorelli D. Diagnosis and treatment of malignant pleural effusion: a systematic literature review and new approaches. Am J ClinOncol 2010:33:420-3.

3. Jantz MA, Antony VB. Pathophysiology of the pleura. Respiration 2008;75:121-33.

4. Froudarakis $M E$, Klimathianaki M, Pougounias M. Systemic Inflammatory Reaction After Thoracoscopic Talc Poudrage. Chest 2006;129:356-61.

5. Marel M, Zrustova M, Stastny B. The incidence of pleural effusion in a well-defined region. Epidemiologic study in central Bohemia. Chest 1993;104:1486-9.

6. Schag CC, Heinrich Ganz PA. Karnofsky performance status revisited Reliability, validity, and guidelines. J Clin Oncology 1984;2:187-93.

7. Montes JF, Ferrer J, Villarino MA. Influence of talc dose on extrapleural talc dissemination after talc pleurodesis. Am J Respir Crit Care Med 2003;168:348-55.

8. Idell S. The pathogenesis of pleural space loculation and fibrosis. Curr Opin Pulm Med 2008;14:310-5.

9. Huggins JT, Doelken P, Sahn SA. The unexpadable lung. Med Rep 2010;2:77.

10. Janssen JP, Collier G, Astoul P, Tassi GF, Noppen M, RodriguezPanadero F, Loddenkemper R, Herth FJ, Gasparini S, Marquette $\mathrm{CH}_{\text {, }}$ Becke B, Froudarakis ME, Driesen P, Bolliger CT, Tschopp JM: Safety of pleurodesis with talc poudrage in malignant pleural effusion: a prospective cohort study. Lancet 2007;369:1535-9.

11. Rodriguez-Panadero F, Montes-Worboys A. Mechanisms of pleurodesis. Respiration 2012;83:91-8.

12. Marchi E, Vargas FS, Acencio MMP, Teixeira LR, Antonangelo L, Lee YCG, Light RW. Pleurodesis: A novel experimental model.Respirology 2007;12(4):500-4.

13. Webb HE, Osten SW.Treatment of malignant ascites and pleural effusions with Corynebacterium parvum. Br Med J 1978;1:338-40.

14. Hoffeld JT. Inhibition of lymphocyte proliferation and antibody production in vitro by silica, talc, bentonite or Corynebacterium parvum: involment of peroxidative processes. Eur J Immunol 1983;13:364-9.

15. Dresler CM, Olak J, James E. Herndon JE, Richards WG, Scalzett E, Fleishman SB, Kernstine KH, Demmy T, Jablons DM, Kohman L, Daniel TM, Sugarbaker DJ. Phase III Intergroup Study of Talc Poudrage vs Talc Slurry Sclerosis for Malignant Pleural Effusion. Chest 2005;127(3):909-15.

16. De Campos JR, Vargas FS, Werebe E. Thoracoscopic talc poudrage: a 15-year experience. Chest 2001;119:801-6.

17. Davies R, Skidmore JW, Griffiths DM, Moncrieff CB: Cytotoxicity of talc for macrophages in vitro. Food Chem Toxicol 1983;21:201-7.

18. Idris L, Ranaweera N, Laws D. Investigation of pleural effusions. Acute Med 2011;10:216-20.

19. Porcel JM. Pearls and myths in pleural fluid analysis. Respirology 2011;16:44-52.
20. Rodriquez-Panadero F, Lopez-Mejitaz J. Survival time of patients with pleural metastatic carcinoma predicted by glucose and $\mathrm{pH}$ studies. Chest 1989;95:320-4.

21. Heffner JE, Nietert $P$, Barbieri C. Pleural fluid $\mathrm{pH}$ as a predictor of pleurodesis failure: analysis of primary data. Chest 2000;117:87-95.

22. Huseyin $Y$, Muzaffer M, Selma M, Sinan E. Predictors of talc pleurodesis outcome in patients with malignant pleural effusions. Lung Cancer 2008;62:139-44.

23. Uzbeck MH, Almeida FA, Sarkiss MG, Morice RC, Jimenez CA, Eapen GA, Kennedy MP. Management of malignant pleural effusions. Adv Ther 2010;27:334-7.

24. Bielsa S, Hernández P, Panadero FR, Taberner T, Salud A, Porcel JM Tumor Type Influences the Effectiveness of Pleurodesis in Malignant Effusions Lung 2011;189(2):151-5.

25. Acencio MMP, Vargas FS, Marchi E, Carnevale GG, Teixeira LR, Antonangelo L, Broaddus VG. Pleural Mesothelial Cells Mediate Inflammatory and Profibrotic Responses in Talc-induced Pleurodesis. Lung 2007;185(6):343-8.

26. Razonable RR, Henault M, Paya CV. Stimulation of toll-like receptor 2 with bleomycin results in cellular activation and secretion of proinflammatory cytokines and chemokines. Toxicol Appl Pharmacol 2006;210:181-9.

27. van den Heuvel MM, Smit HJ, Barbierato SB, Havenith $C E$, Beelen $\mathrm{RH}$, Postmus PE. Talc-induced inflammation in the pleural cavity. Eur Respir J 1998;12:1419-23.

28. Nasreen N, Hartman DL, Mohammed KA, Antony VB. Talc-induced expression on $\mathrm{C}-\mathrm{C}$ and $\mathrm{C}-\mathrm{X}-\mathrm{C}$ chemokines and intercellular adhesion molecule-1 in mesothelial cells. Am J Respir Crit Care Med 1998;158:971-8.

29. Antony VB, Nasreen N, Mohammed KA, Sriram PS, Frank W Schoenfeld N, Loddenkemper R. Talc pleurodesis: basic fibroblast growth factor mediates pleural fibrosis. Chest 2001;126:1522-8.

30. Cassatella MA. The production of cytokines by polymorphonuclear neutrophils. Immunol Today 1995;16:21-6.

31. Sirisinha S. Insight into the mechanisms regulating immune homeostasis in health and disease. Asian Pac J Allergy Immunol 2011;29:114.

32. Montes-Worboys A, Rodriguez-Potal JA, Arellano-Orden E, DigónPereiras J, Rodriguez-Panadero F. Interleukin-8 activates coagulation and correlates with survival after talc pleurodesis. EurRespir J 2010:35:160-6.

33. Delongu G, Moretti S, Antonucci A. Apoptosis and surgical trauma. Arch Surg 2000;135:1141-7.

34. Christensen R, Bradley PP, Rothstein G. The leukocyte left shift in clinical and experimental neonatal sepsis. J Pediatr 1981;98:101.

35. Levy JH, Tanak KA. Inflammatory response to cardiopulmonary bypass. Ann Thorac Surg 2003;75:715-20.

36. Akbas H, Erdal C, Demiralp E, Alp M. Effectsofcoronaryartery bypass grafting on cellular immunity with or without cardiopulmonary bypass: changes in lymphocytes subsets. Cardiovasc Surg 2002;10(6):586-9.

37. Yang HB, Xie KQ, Deng JM, Qin SM. Expression of soluble Toll-like receptors in pleural effusions. Chin Med J 2010;123:2225-30.

38. Chang LC, Hua CC, Chu CM, Chiang BY, Chen HJ, Yu CC. Differentia mRNA expression of Toll-like receptors and their adaptors in pleural effusions. Respirology 2009;14:1194-9.

39. Acorci-Valério MJ, Bordon-Graciani AP, Dias-Melicio LA, de Assis Golim M, Nakaira-Takahagi E, de Campos Soares AM. Role of TLR2 and TLR4 in human neutrophil functions against Paracoccidioides brasiliensis. Scanc J Immunol 2010;71:99-108.

40. Hidaka M, Fukuzawa K. Down-modulation of toll-like receptor 2 expression on granulocytes and suppression of interleukin-8 production due to in vitro treatment with cellulose acetate beads. Ther Apher Dial 2011;15:572-8.

41. Krejsek J, Kunes P, Kolackova M, Kudlova M, Lonsky V, Mandak J, Andrys $C$. Expression of Toll-like receptors 2 and 4 on innate immunity cells modulated by cardiac surgical operation. Scand J Clin Lab Invest 2008;68:749-58.

42. Onofre G, Kolackova M, Jankovicova K. Scavenger receptor cd163 and its biological functions. Acta medica (Hradec Kralove) 2009:52(2):57-61.

43. Erridge $C$. Endogenous ligands of TLR2 and TLR4: agonists or assistants? J Leukoc Biol 2010;87:989-99. 